\title{
Bat activity in intensively farmed landscapes with wind turbines and offset measures
}

\author{
Lara Millon ${ }^{1,2}$, Jean-François Julien², Romain Julliard² and Christian Kerbiriou ${ }^{2}$ \\ 1: InVivo Agrosolutions, Direction Technique et Développement, 83 Avenue de la Grande \\ Armée, 75782 Paris, France \\ 2: Muséum National d'Histoire Naturelle, Centre d'Ecologie et des Sciences de la \\ Conservation, UMR 704 MNHN-CNRS, 55 rue Buffon, 75005 Paris, France
}

\section{Corresponding author: Lara Millon, lara.millon@gmail.com}

\begin{abstract}
Compensation measures are needed to counteract some of the negative impacts of wind energy facilities on bat populations. To advise developers, we studied farming landscapes and compared bat activity at impacted sites (crops with wind turbines), sites without compensation measures (crops) and a set of sites with potential compensation measures: fallows, hedgerows, bushes, grass strips, and grass strips with bushes. Each site type was sampled twice in 2013, once during the reproductive period and once during the migratory period. Each sample consisted of at least 8 nights of ultra-sound recordings. Bat species were separated into 3 groups: Pipistrellus $s p$, Eptesicus-Nyctalus $s p$ and Plecotus-Myotis $s p$. The results demonstrated that the 3 groups responded differently to the different potential compensation measures and that responses were season-dependent. These results lead to further questions regarding strategies to mitigate the negative impacts of wind farms.
\end{abstract}

\section{Keywords}

Bats; wind turbines; mitigation; Agri-Environmental Scheme; ecological equivalence; Generalized Linear Mixed Models

\section{Highlights}

- Energy production from renewable resources is useful for decreasing greenhouse gas emissions; however, the negative impacts on biodiversity require measures to mitigate their effects.

- Bat activity was compared between sites impacted by wind energy facilities, sites with possible compensation measures and control sites (i.e., those without wind turbines or compensation measures).

- The 3 groups of bats showed different season-dependent responses to compensation measures.

- These results highlight the fact that questions remain concerning how compensation measures could be implemented to be effective for different ecological niches.

\section{Introduction}

Today, it is well known that the human population demands more and more energy, which increases the emissions of greenhouse gases and reduces the availability of natural habitat. Due to this alarming situation, following the Kyoto conference, a global objective has been to reduce emissions of greenhouse gases (GHG). Among the possible solutions, the 
production of electricity from renewable energy sources has been identified as a priority (Kuvlesky et al., 2007). Wind turbines are a part of alternative energy production that does not contribute to greenhouse gas emissions (Barclay et al., 2007, Kuvlesky et al., 2007). Worldwide, between 2001 and 2009, wind energy increased 6.5-fold in installed capacity (WWEA 2010). In Europe, onshore wind is expected to be the largest contributor to achieving 20\% renewable electricity by 2020 in Europe (Directive 2009/28/EC). Although the impact of wind turbines on the ground is not great compared to other development projects, the growth of the wind energy industry does not come without concerns. Indeed, bird and bat fatalities induced by wind turbine blade rotation are regularly described in Europe (Rodriguez et al., 2008) and North America (Baerwald \& Barclay., 2009, Erickson et al., 2002, Johnson et al., 2003, Kunz et al., 2007a, Kuvlesky et al., 2007). In addition, wind turbines may cause non-lethal impacts, such as disturbance of commuting and migration routes, displacement and local habitat loss (Hötker et al., 2006, Kunz et al., 2012, Kuvlesky et al., 2007, Roscioni et al., 2014).

Wind farm developers are obligated to provide effective avoidance, reduction, on-site restoration and offset measures (EC 2007) in order to achieve no net loss of biodiversity or a net environmental benefit. Offsetting, the last step of the Avoiding-Reducing-Offsetting sequence, consists of implementing measures that counteract the residual loss of biodiversity and generate gains through management measures (e.g., restoration or creation of habitats on offset sites, land acquisition and/or the legal protection of areas) (McKenney \& Kiesecker 2010, Maron et al., 2012). This produces the so-called ecological equivalence between biodiversity losses (i.e., residual effects after avoidance and reduction measures) and biodiversity gains through the implementation of offset measures (Quetier \& Lavorel 2011, Regnery et al., 2013a). Mitigation policies explicitly stated that "in-kind compensatory mitigation is preferable to out-of-kind" (US EPA and DA 1990, McKenney \& Kiesecker 2010); that is, offset frameworks should be spatially and ecologically as close as possible to the impacted area (McKenney \& Kiesecker 2010). This obligation has resulted in legislation that allows for derogation from strict protection to licenses allowing activities with the obligation to mitigate any potential negative effects (see for Stone et al., 2013 for England or Regnery et al., 2013a for France). In England, a recent study (Stone et al., 2013) concluded that it was unclear whether the licensing process meets EU obligations concerning bats.

A particularly interesting situation, which is far from trivial, is wind turbines installation in intensive agricultural landscapes, and the associated research on offset measures for biodiversity. Indeed, due to constraints resulting from cultural or natural heritage (e.g., the Landscape Act, Coastal Act, Areas of Conservation (SACs) and protected areas) and the reluctance of local people to install wind turbines near their homes, project developers often attempt to install wind energy facilities on agricultural land, particularly in arable land dominated by open fields. However, intensive agriculture is recognized as one of the greatest current threats to worldwide biodiversity (Benton et al., 2003, Hole et al., 2005) even without wind turbines. Thus, there is a great need to find measures that have positive impacts on biodiversity in order to improve biodiversity-friendly farming and counteract the negative impacts of wind turbines close to impacted areas. Today, agri-environment schemes (AES) are implemented in Europe when farmers subscribe to environmental commitments related to the preservation of the environment, such as hedgerows, bushes or grass strips (Kleijn \& Sutherland 2003). However, their positive impacts on biodiversity are discussed (Kleijn et al., 2006, Kleijn \& Sutherland 2003, Whittingham 2011). Implementations of both offset measures and AES in farming landscapes have the common 
goal of bringing about biodiversity gains and it would be wise to assess the additionality of these two managements.

Therefore, we proposed to evaluate the non-lethal impacts of wind energy facilities on bat populations (i.e., reductions in availability and attractiveness of foraging habitat) and to assess the consequences of setting up vegetation structures which are aimed at ecological mitigation of wind turbines in intensively farmed landscapes. We decided to focus on bat populations for the following reasons. First, European bats are endangered throughout much of their range (Stebbings 1988, UICN 2011). Numerous threats and causes of this decline have been identified and include the availability of suitable foraging habitat (Walsh \& Harris 1996, Kunz \& Fenton 2003), agricultural intensification, which has resulted in an increase in pesticide use (Dunsmore et al., 1974, Jones et al., 2009, Swanepoel et al., 1999, Wickramasinghe et al., 2003), land use changes (Stebbings 1988, Battersby 2010), roost destruction and disturbance (Mitchell-Jones et al., 2007); artificial lighting (Rydell 2006, Stone et al., 2012), global climate change (Jones et al., 2009) and wind energy fatalities (Kunz et al., 2007b, Racey 2009, Rodriguez et al., 2008). Most bats killed at wind energy facilities across Europe belong to the genera Pipistrellus and Nyctalus (Amorium et al., 2012, Hötker et al., 2006) and to a lesser extent genus Eptesicus and Vespertilio have also high fatality rates (Rydell et al., 2010). Despite numerous and recent published studies relating bat fatalities due to wind turbine, quantification of this impact on mortality and population dynamics remain difficult. High rates of bat fatalities are worrying because bats have slow life-histories (Barclay and Harder 2003). Second, to the best of our knowledge, very few studies have been carried out on the indirect impacts of wind farms (i.e., disturbance, displacement, reduction of availability and attractiveness of foraging habitat) on bat populations (Bach 2002). This knowledge gap renders our study highly valuable because such impacts should also be included when calculating equivalence. Third, bats are considered to be bio-indicators, and based on the importance of common species for ecosystem functioning, offset measures are necessary to counteract the negative effects on those species as well (Regnery et al., 2013b, Jones et al., 2009). Fourth, few studies have been carried out on bat populations or their prey in intensively farmed landscapes (Boughey et al., 2011, Jennings \& Pocock 2009, Lentini et al., 2012, Merckx et al., 2009, Raihno 2007, Taylor \& Morecroft 2009). For instance, most studies on the impacts of AES concerned birds, insects and plants (Kleijn et al., 2006, Kleijn \& Sutherland 2003, Whittingham 2011).

Our analysis focused on a comparison of bat activity at impacted sites (crops with wind turbines), sites without compensation measures (crops) and sites with a set of potentially compensation measures (crops with agricultural fallows and crops with semi-natural elements linked to local farming practices, such as hedgerows, bushes, grass strips, etc.). We did not limit our study to threatened species but considered the whole bat community, focusing on three groups (Pipistrellus sp, Eptesicus-Nyctalus sp and Plecotus-Myotis sp).

\section{Methods}

\subsection{Study area}

Our study was conducted from May to September, 2013 in Champagne-Ardenne in northeast France (Fig 1); this region is predominantly rural, with agricultural land covering $68 \%$ of the territory, urban areas $3 \%$ and woods and natural land less than $29 \%$, as 
calculated from Corine Land Cover data. The agricultural fields are mainly used for intensive cropping, especially for cereals, sugar beet and rapeseed. The region is ranked fourth in France for wheat production (INSEE 2012), and 32\% of its Utilized Agricultural Land is dedicated to cereal production (AGRESTE 2012). In 2012, the Champagne-Ardenne region was ranked second in France for producing electricity from wind and was able to produce the equivalent of almost $70 \%$ of its domestic consumption this way (ENR 2012).

\subsection{Bat inventory}

Fieldwork was carried out during two visits, corresponding to seasonal peaks in bat activities, as recommended by the French Bat Monitoring Program (FBMP 2012). The first visit occurred during the period in which females give birth and feed their offspring (late May to early July). In contrast, bats that were a few months old and already hunting and migratory adults were expected to be contacted during the second visit (middle of August to end of September). We sampled bats using standardized echolocation recordings on stationary points, which is a robust method to assess the relationship between bat activities and the corresponding habitat (Stahlschmidt et al., 2012). For more technical details on bat monitoring see Supplementary material $A_{-} 1$.

At each sampled time point, we recorded all sounds higher than $12 \mathrm{KHz}$ throughout the entire night, from 30 minutes before sunset to 30 minutes after sunrise. Three ultra-sound detectors with identical settings were used each night. We used Scan'R (Binary Acoustic Technology, 2010) to isolate each bat vocalization and automate the measurement of relevant parameters (Barataud 2012; Gannon et al., 2004; Obrist et al., 2004, see Supplementary material $A_{-} 2$ ). Ambiguous call patterns were analyzed call by call by authors using Syrinx software version 2.6 (Burt, 2006). Due to the lack of general consensus for some species about the acoustic criteria and some overlap between acoustic repertoires, it was not possible to assign the exact species with certainty for all calls; thus, we constructed three groups: Pipistrellus (Pipistrellus kuhlii, P. nathusii, P. pipistrellus and P. pygmaeus), Eptesicus-Nyctalus (Eptesicus serotinus, Nyctalus leisleri and N. noctula) and Plecotus-Myotis (Myotis bechsteinii, M. daubentonii, M. myotis, M. nattereri, M. species, Plecotus auritus and $P$. austriacus). For more details on the composition of each group, see Supplementary material A_4. Note that some species included in the same group may have different ecology, however, from a foraging behavior perspective, these groups have some convergences. The Plecotus-Myotis group primarily included species considered to be gleaners, which capture the majority of their prey from substrates in cluttered environments (Arlettaz et al., 2001). These species eat mainly diurnal brachyceran Diptera and non-volant arthropod such as weevils, lepidopteran larvae, harvestmen and spiders (Swift \& Racey, 2002, Dietz et al., 2007). In contrast, the Pipistrellus and Eptesicus-Nyctalus groups primarily included species considered to be aerial hawkers, which forage mostly on flying prey in open spaces (Dietz et al., 2007, Schnitzler et al., 2003, Holderied \& Von Helversen, 2003). These two groups can be distinguished according to their flight height: Pipistrellus ssp. forage on average at a lower altitude than Eptesicus ssp and Nyctalus ssp (Rydell 2006). These groups also exhibited consistency with respect to detection distance; the Plecotus-Myotis group included mainly species detected from 5 to $15 \mathrm{~m}$, the Pipistrellus group from 20 to $25 \mathrm{~m}$ and the Eptesicus-Nyctalus group from 30 to 100 m (Barataud 2012). Finally, some species having 
been recorded on too few sites, their statistical analysis would not have been satisfactory and required to be grouped.

As it is impossible to know the exact number of individuals foraging in the areas, we used a bat activity metric instead (bat passes), calculated as the number of contacts per night per group. For each group, a pass was defined as a single bat call or several bat calls emitted during a 5 second interval; if the calls were emitted for longer than 5 seconds, they were counted as 2 passes. Because the absolute length of a bat pass mainly depends of the detection distance, some species are recorded for longer time than other (e.g. Nyctalus ssp versus Pleocotus ssp and Myotis ssp). However, data from the FBMP indicate the 5 seconds interval is quite a good compromise (see Supplementary material $A_{-} 3$ ).

\subsection{Sampling design}

To assess the potential disturbance of wind energy facilities, bat activity was compared between impacted sites (Crops under wind turbine, CWT, $\mathrm{n}=12$ ) and non-impacted areas (Crops without wind turbine, $\mathrm{C}, \mathrm{n}=12$ ). Second, to evaluate potential offsets of wind turbine settlement in an agricultural landscape, we compared bat activity in areas with alternative agricultural practices such as fallows $(\mathrm{Fa}, \mathrm{n}=8)$ and in agricultural landscape elements such as a representative set of hedgerows $(H, n=8)$, grass strips $(G S, n=8)$, bushes $(B, n=8)$ and grass strips with bushes (GSB, $n=8$ ). All sample sites were located more than $200 \mathrm{~m}$ from each other.

\subsubsection{Characteristics of sites}

Crops under wind turbine were located in a 7 square kilometer park containing 30 wind turbines (the "Germinon" site). Wind turbines had a 100 meter-high tower and 50 meterlong blades and were located in crop fields. Some crops without wind turbine were located in the area surrounding the 30 wind-turbine park (at a minimum distance of $880 \mathrm{~m}$ and a maximum distance of $2.4 \mathrm{~km}$ from the closest wind turbines). The others crops without wind turbine were located in the "Symbiose" site (at $35 \mathrm{~km}$ from "Germinon"), an area where alternative agricultural practices and landscape elements have been commonly implemented.

Fallows were areas that were mowed at most twice a year. Their average surface was $3 \pm 1$ ha, and they were $0.87 \pm 0.07 \mathrm{~m}$ high. Hedgerows were composed of approximately 15 shrub species, including usually tree species, mostly broad-leaved species $(6 \pm 0.7 \mathrm{~m}$ high). Hedgerows also included double rows of trees. On average, the sampled hedgerows were $537 \pm 97 \mathrm{~m}$ long and $6.5 \pm 1.6 \mathrm{~m}$ wide. Grass strips were $6.5 \pm 1 \mathrm{~m}$ in width and $600 \pm 66 \mathrm{~m}$ long. They were either sowed or left to natural growth and mowed at most twice per year to avoid fallow land encroachment. Bushes consisted of a mix of 6 broad-leaved shrub species planted in the middle or at the edge of the crops; they were $7 \pm 0.8 \mathrm{~m}$ long, $2.6 \pm 0.2 \mathrm{~m}$ high and 2.8 $\pm 0.3 \mathrm{~m}$ wide. Similar bushes but in longer stretches (18.5 $\pm 2.7 \mathrm{~m}$ long, $2.1 \pm 0.13 \mathrm{~m}$ high and $2 \pm 0.25$ wide) were planted inside grass strips at, on average, 100 meter intervals. The grass strips with bushes were $5.6 \pm 0.3 \mathrm{~m}$ wide and $757 \pm 56 \mathrm{~m}$ long; they received the same management protocol as the Grass strips. In total, 60 sampling sites were identified. Due to changes in farming management during the season, 7 of the 8 fallows and 7 out of 8 hedgerows were present at the second visit. For technical reasons, only 6 bushes were the same at both the first and second visits. The results demonstrated herein thus consist of a 
smaller sample size from the second visit than the first (only 56 sampling points). However, extra sites were added at the second visit to maintain 8 hedgerows, 8 bushes and 10 fallows. We obtained similar results from this data set (see Supplementary material B).

\subsubsection{Habitat and local field characteristics}

Because bat activity could depend on landscape structure beyond the focal compensation measure of interest, the position of the 60 sampling points was chosen according to the surrounding habitat. Distances to the nearest forest, river or urban area, as a proxy for landscape characteristics, were checked to ensure homogeneity among site types (see Supplementary material $C_{-} 1$ ); landscape data were provided by the National Institute of Geography (from BD TOPO for data on forests and urban areas and from BD Carthage for river data (www.ign.fr); distance and areas were calculated using ArcGIS 10.1). Only the fallows were, on average, too close to forests during the first visit, rendering the distribution of this variable heterogeneous among site types $(k s=14.9, p=0.0214$, see Supplementary material C_1). However, this is also representative of what is found in farming practices in the area; fallows are usually implemented close to forests because those areas are generally less accessible.

In addition to large scale habitat structure, local field characteristics within a $100 \mathrm{~m}$ buffer area were also taken into account; the crops' mean height was noted in addition to the number and type of crops in the fields and the presence of farming trails and marginal strips of spontaneous herbaceous. Because those variables reflected the local landscape's heterogeneity, they might have had an effect on species' abundances. Only variables describing local field characteristics, which did not correlate with site type, were selected (see Supplementary material C_2). To avoid over-parameterization, only 3 among them were included in the statistical models. We used hierarchical partitioning of variance (HP, R package hier.part) to choose the ones that explained the largest portion of the variance. This method is an analytical method using multiple regressions that allows us to identify the most likely causal factors while alleviating multicollinearity problems (Mac Nally 2000).

\subsubsection{Meteorological variables and material used}

Because we assumed that bat activity might be affected by weather conditions (Ciechanowski et al., 2007), recordings were only performed when weather conditions were favorable, i.e., no rain, low wind speed $(<7 \mathrm{~m} / \mathrm{s})$ and temperatures, if possible, higher than $12^{\circ} \mathrm{C}$ half an hour after sunset (FBMP 2012). To reduce statistical effects of meteorological variables, the three ultra-sound detectors were used as much as possible on different site types during the same night. In addition, we also recorded precipitation, wind speed, temperature at $8 \mathrm{PM}$ and luminosity during the night (for more details concerning this last variable, see Supplementary material $C_{-} 3$ ). The date was also noted and transformed into a numeric variable, i.e., a Julian date. To avoid a correlation between the sampling dates and site types, the sampling design included alternating among sampled site types over time. Among the meteorological variables most likely to affect bat activity, 2 were included in the models. The choice of variables was made after having checked their distribution among site types, assessed the correlation between them and performed a hierarchical partitioning of variance ( $\mathrm{R}$ package hier.part, see Supplementary material $C_{-} 4$ and $C_{-} 5$ ). 
Finally, to avoid a correlation between the material used and the site type, the three detectors were used to sample all site types in quasi-equal numbers. The detector used (serial number) and the lengths of the recording time were noted. Among those two last variables, one was chosen to be included in the models after the hierarchical partitioning of variance (see Supplementary material $C_{-} 6$ ).

\subsection{Statistical analyses}

Because each visit represents two different periods of bat activity, analyses were performed separately for each visit. In the first step, each group's number of calls was analyzed. In the second step, a dataset including all groups was analyzed, but each group was distinguished. At the species group level, during each visit, we assessed variations in bat activity (i.e., the response variable) as a function of site type, local field characteristics, weather conditions and material variables (i.e., explanatory variables) using generalized linear models (GLM). The effect of site type was adjusted to the other explanatory variables using an Anova type II ( $R$ package car). Because of the nature of the data (i.e., count data), we performed GLMs with a Poisson error distribution. Following Faraway (2006), p-values were corrected for potential overdispersion using a dispersion parameter. For the analyses of the full dataset, we used mixed generalized linear models for each visit, which included the group of species as a random effect ( $\mathrm{R}$ package Ime4).

All selected variables (local field characteristics, meteorological variables and material variables) were included in the first model. We removed the ones that did not have a significant effect one by one. Our final models included the variable site type in addition to the others variables that had a significant effect (see Supplementary Material $D$ to know the list of the selected variables and their explanatory power, plus the AIC of the final models). In addition to the selection procedure for the variables, which aimed to select variables of interest, avoid over-parameterizations and avoid including correlated explanatory variables, we evaluated multicollinearity in the explanatory variables of our final models by calculating variance-inflation factors (VIF) on the full models (Fox \& Monette 1992). All variables had VIF<2. Because recordings could be from the same night but different site types (i.e., for 85 $\%$ of the nights), another type of statistical analysis was used that considered data from the same date as paired and thus allowed removal of the meteorological variables by including an adjustment for date, taken as a factor. Similar results were found (see Supplementary Material E).

We explored data for potential spatial autocorrelation using a variogram tool ( $R$ package spatial, Bivand et al., 2008). According to the slight spatial trend detected for the Pipistrellus group at the first visit $(P$-value $=0.019)$ and the Eptesicus-Nyctalus group at the $1^{\text {st }}$ visit $(P$ value $=0.00013$ ), we added an autocovariate (i.e., a distance-weighted function of neighboring response values, here weights by the square of inverse distance; Dormann et al., 2007, Penone et al., 2013) with the autocov dist function in R for those two group's analysis and the mixed generalized linear models for the $1^{\text {st }}$ visit (package spdep, Roger Bivand).

Bat activity in crops without wind turbine was used as the reference (i.e., intercept) in our models. This permitted us to easily assess the impact of wind turbines in agricultural landscapes on bat activity. Moreover, it permitted us to determine the gain or loss incurred from changing agricultural practices or adding landscape elements to intensively farmed 
landscapes. All analyses were performed using $R$ statistical software v.3.0.2 (The $R$ foundation for Statistical Computing, 2013).

\section{$\underline{3 \text { Results }}$}

\subsection{Species registered}

In total, more than 9900 bat passes were recorded, 3926 during the first visit and 5985 during the second. The majority of them were from species in the Pipistrellus group (Table 1). For more details on the composition of each group, see Supplementary material A_4.

\subsection{Effects of wind turbines}

Bat activity was, on average, lower in crops under wind turbine than in crops without wind turbine for all groups and all visits (Table 2). This was confirmed with significant results in the analysis of the total dataset (Fig 2, see Supplementary material F).

Because some of the crops without wind turbine were not in the area surrounding the wind turbine farm at the Germinon site, we performed analyses on a subset of the data that included crops under wind turbine and crops without wind turbine from the Germinon site. The variables used were the same as in the models with all the data. A significant difference was again found for the second visit $(\beta=-2.09 \pm 0.11, p$-value $<0.0001)$. However, for the first visit, we did not detect any significant effect ( $p$-value $=0.29)$.

\subsection{Effects of offsets and farming practices}

During the first passage, at the species group level, at least one farming practice or landscape element resulted in a gain in each group (Table 2). The Pipistrellus group was slightly positively impacted by the presence of hedgerows, the Eptesicus-Nyctalus group by hedgerows and grass strips, and the Plecotus-Myotis group by fallows. When taking into account all groups, fallows and hedgerows resulted in a significant gain $(\beta=0.54 \pm 0.06, p$ value $<0.0001$ and $\beta=0.70 \pm 0.05, p$-value $<0.0001$, respectively, Fig 2 , see Supplementary material F). During the second visit, at the species group level, fallows resulted in an increase in Pipistrellus, whereas the grass strips and grass strips with bushes induced a significant decrease in Pipistrellus and Eptesicus-Nyctalus (Table 2). When considering all groups in the same analysis (Fig 2, see Supplementary material $F$ ), fallows induced a significant positive effect $(\beta=0.85 \pm 0.05, p$-value $<0.0001)$, accompanied by bushes $(\beta=0.18 \pm 0.04, p$-value $<0.0001)$. Hedgerows were associated with a decrease in bat activity at the end of the summer $(\beta=-1.22 \pm 0.07$, $p$-value $<0.0001)$. Grass strips had no impact during the first visit ( $p$ value $=0.538)$ but induced a significant decrease during the second visit $(\beta=-0.93 \pm 0.06, p$ value $<0.0001)$. Grass strips with bushes had a significant negative effect during both the first $(\beta=-0.32 \pm 0.07, p$-value $<0.0001)$ and second visits $(\beta=-0.93 \pm 0.06, p$-value $<0.0001)$.

\section{Discussion}

Bat activity was, on average, lower in crops under wind turbine than in crops without wind turbine for all groups and whatever the season considered. But the 3 groups of bats showed different responses to compensation measures: during the reproductive season, Plecotus- 
Myotis group was positively impacted by fallow, whereas Pipistrellus and Eptesicus-Nyctalus responded positively to hedgerow. This latest bats group responded also positively to grass strips. In addition, we also detected season-dependent responses to compensation measures: significant changes of responses were observed for hedgerow and bushes, for which bats responses were the opposite according to season.

\subsection{Limits}

An approach targeted to feeding buzzes would most likely be more appropriate because it would be more tightly linked to resources that are vital to bats. However, due to the limited observations of feeding buzzes collected, we used the total number of bat passes per night as a proxy for bat activity. Additionally, data were only collected during one year. Multiannual dynamics were therefore not taken into account. Finally, the site types that were sampled were different in size and age, which could explain some of the observed differences. However, we tried to choose older sites for this study to limit the heterogeneity but the differences are also representative of what is actually implemented in farming landscapes (Fallows, Hedgerows, Grass strips, bushes, grass strips with bushes). Further analyses and sampling could determine the size that would be most effective.

\subsection{Effects of wind energy facilities}

Many studies have highlighted the impact of wind turbine on bat through bat fatalities (Johnson et al., 2003, Kunz et al., 2007a \&2007b, Kuvlesky et al., 2007). However to our knowledge, this study is one of the first to demonstrate that wind energy facilities can have a negative impact on bat activity through a measure of bats activity in intensive agricultural sites which differ by the presence or not of wind turbine. This sampling (points outside a wind turbine park with those inside of it) permitted us to avoid a temporal bias that exists when comparing data from before versus after the implementation of a wind turbine park. However, the sampling design used did not permit us to completely avoid a site bias because the sampling was conducted on two sites, Germinon and Symbiose. To counteract this bias, we performed an analysis on a restricted dataset that included only the site with the wind farm (Germinon) to compare bat activity with and without wind turbines. Those results showed that a negative effect of wind turbines, which was found during the first visit, was not detected. However, the negative impact during the second period was still detectable, suggesting that individuals avoided the wind turbine park during this period. This difference between the two visits when focusing only on the site with a wind farm could be linked to a sample effect (i.e., smaller sample size), but a non-exclusive hypothesis could also indicate a real difference in bat behavior. Indeed, during the first visit (late May to early July), sites are expected to be used by reproductive individuals present in the region, with high fidelity between years; there is thus the possibility of a behavioral adaptation to use this habitat without being injured by turbines. This is consistent with a previous study that showed that Pipistrellus pipistrellus, the most abundant species in our study, became habituated to wind turbines (Bach 2002). In contrast, during the second visit (from the middle of August to the end of September), populations are expected to include non-local individuals such as migrating bats. This avoidance behavior may seem contradictory to some studies that showed that bats were attracted by wind turbines for roosting or foraging (Northrup \& Wittemyer, 2013) or link to mating behavior (Cryan 2008). This difference in results may 
indicate that there are two effects of wind turbines, one repulsive at the scale of the wind farm (30 wind turbines over $7 \mathrm{~km}$ square) and one attractive at the scale of the turbine itself (tree-roosting bats mistake wind turbines for roost trees while engaging in mating behaviors, insectivorous bats feed on insects that might be attracted by wind turbines or other bat species might be attracted by the swishing sounds produced by the rotating blades (Cryan 2008, Cryan \& Barclay, 2009, Cryan et al., 2014, Horn et al., 2008, Kunz et al., 2007b, Rydell et al., 2010).

\subsection{How to define offset measures}

Many previous studies were not designed to directly test management strategies that could be used as mitigation measures (Northrup \& Wittemyer 2013). This study was designed to evaluate the effects of offset measures in order to advise developers. We expect that by offering a choice of offset measures with explicitly equivalent outcomes, we place the agricultural stakeholders in the center of the offsetting process; this would undoubtedly contribute to the successful implementation of compensation measures. In addition, the research on offset measures based on field metrics of biodiversity with sound and transparent sampling designs, using the same methods to assess the losses caused by the operation of wind farms and the potential gains from some agricultural practices may reduce the opposition to the proposed offsets.

It has been hypothesized that agriculture intensification is a major cause of bat population declines (Stebbings 1988). Some studies showed that bat activity was higher on organic farms than on conventional ones (Wickramasinghe et al., 2003), but we cannot know if this was due to a reduction in agrochemical use in organic farms or a larger amount of hedgerows (Jones et al., 2009). Lentini et al. (2012) proved that, in farming landscape, larger linear remnant with intact native vegetation supported higher bat activity. FuentesMontemayor et al. (2011) compared the effects of Agri-Environmental Scheme (AES) interventions on Pipistrellus pipistrellus and Pipistrellus Pygmaeus with similar interventions that were not implemented as an AES. They found that both food availability and bat activity were lower on farms with AES interventions. Here, the effects of agricultural fallows and different landscape elements on the activity of three groups of bats were compared with conventional farming practices. We showed that those site types could have a significant positive impact on bat activity (Table 2, Fig 2).

We identified that fallows and hedgerows, especially in spring and early summer, could bring about gains and therefore be used to achieve the no-net-loss objective within the framework of "like-for-like" offsetting practices for protected species. At the landscape scale, the establishment of fallows and hedgerows could help to conserve the impacted species by improving ecological conditions outside of the impacted site. However, we showed that those groups responded differently to the different site types and that responses were period dependent (Table 2, Fig 2). Farm management could cause the difference between the two visits. Indeed, most of the crops were mowed when the second visit occurred, making the site types more disconnected from the landscape elements. We believe that hedgerows were the site type that became the most disconnected, leading to a positive effect in the first visit and a negative one in the second (Fig 2). This observation is congruent with a study by Boughey et al., (2011) that emphasized that landscape context may influence the use of linear features. Fuentes-Montemayor's (2011) results highlighted 
that the management of implementations, such as an AES or an offset measure, should be carefully designed in order to have an effective positive impact on bat populations.

\section{Conclusion}

These results highlighted the facts that wind energy facilities have a negative impact on bat activity, proving that a repulsive effect at the scale of the wind does exist. This loss of habitat is rarely taken as a serious threat (Lloyd, 2010) and mitigation strategies are usually only based on bat fatalities. We showed here that the loss of foraging habitat has to be taken into account when assessing offset measures to counteract the negative impacts of wind energy facilities.

These results lead also to further questions regarding strategies for mitigating the effects of wind turbines: i) How can we take into account the ecological needs of species that do not respond in the same way throughout the year? Should we promote priority site types that are favorable for the breeding season? Should we perform a mix of site types at the landscape scale? ii) How can we take into account the entire bat community despite the fact that the species do not thrive on the same features? Should we promote priority species whose local population trends are declining fastest or species identified to be the most impacted by wind farms? iii) How can we propose an offset based both on mortality and loss of habitat attractiveness, knowing that wind farm facilities kill bats from near and far (Lehnert et al., 2014.)?

\section{Acknowledgements}

We are grateful to the farmers that let us perform this study on their farm and to the local partnerships (CPIE Pays de Soulaines, Fédération Régionale des Chasseurs de ChampagneArdenne) that advised us throughout the study. We also thank Julien Robak for his help in the field. This work was funded by GDF SUEZ Futures Energies.

\section{References}

AGRESTE 2012. Ministère de l'Agriculture, de l'Agroalimentaire et de la forêt. http://agreste.agriculture.gouv.fr/IMG/pdf_R2111RA01.pdf

Amorim, F., Rebelo, H., Rodrigues, L., 2012. Factors influencing bat activity and mortality at a wind farm in the Mediterranean region. Acta Chiropterologica. 14, 439-457.

Arlettaz, R., Jones, J., Racey, P.A., 2001. Effect of acoustic clutter on prey detection by bats. Nature. 414, 742-745.

Bach, L., 2002. Auswirkungen von Windenergieanlagen auf das Verhalten und die Raumnutzungen von Fledermäusen am Beispiel des Windparks „Hohe Geest“, Midlum Endbericht. Rapport inédit pour l'Institut für angewandte Biologie, Freiburg/Niederelbe, 46 pp.

Baerwald, E.F., Barclay, R.M.R., 2009. Geographic variation in activity and fatality of migratory bats at wind energy facilities. Journal of Mammalogy. 90, 1341-1349. 
Barataud, M., 2012. Ecologie acoustique des chiroptères d'Europe. Identification des espèces, études de leurs habitats et comportements de chasse. Biotope, Mèze ; Muséum national d'histoire naturelle, Paris (collection Inventaires et biodiversité), $344 \mathrm{pp}$.

Barclay, R.M.R., Baerwald, E.F., Gruver, J.C., 2007. Variation in bat and bird fatalities at wind energy facilities : assessing the effects of rotor size and tower height. Canadian Journal of Zoology. 85, 381-987.

Barclay, R.M.R., Harder L.D., 2003. Life histories of bats: life in the slow lane. Pages 209-253 in T. H. Kunz and M. B. Fenton, editors. Bat ecology. University of Chicago Press, Chicago, Illinois, USA.

Battersby, J. 2010. Guidelines for surveillance and monitoring of European bats. EUROBATS Publication Series No. 5. UNEP / EUROBATS Secretariat, Bonn, Germany, 95 pp.

Benton, T.G., Vickery, J.A., Wilson, J.D., 2003. Farmland biodiversity: is habitat heterogeneity the key? Trends in Ecology \& Evolution. 18, 182-188.

Bivand, R.S., Pebesma E.J., Gomez-Rubio, V. 2008. Applied spatial data analysis with R. Springer, New York, USA, 374pp.

Boughey K.L., Lake L.R., Haysom K.A., Dolman P.M., 2011. Improving the biodiversity benefits of hedgerows: How physical characteristics and the proximity of foraging habitat affect the use of linear features by bats. Biological Conservation. 144, 1790-1798.

Burt, 2006. Syrinx a software for real time spectrographic recording, analysis and playback of sound. http:/www.syrinxpc.com.

Cryan, P.M. 2008. Mating behavior as a possible cause of bat fatalities at wind turbines. The Journal of Wildlife Management. 72, 845-849.

Cryan, P.M., Barclay, R.M.R. 2009. Causes of bat fatalities at wind turbines: Hypotheses and predictions. Journal of Mammalogy. 90, 1330-1340.

Cryan, P.M., Gorrensen, P.M., Hein, C.D., Schirmacher, M.R., Diehl, R.H., Huso, M.M., Hayman, D.T.S., Fricker, P.D., Bonaccorso, F.J., Johnson, D.H., Heist, K., Dalton, D.C., 2014. Behavior of bats at wind turbines. PNAS. 111, 15126-15131.

Ciechanowski, M., Zajac, T., Bilas, A., Dunajski, R., 2007. Spatiotemporal variation in activity of bat species differing in hunting tactics: effects of weather, moonlight, food abundance, and structural clutter. Revue canadienne de zoologie. 85, 1249-1263.

Dietz, C., Nill, D., Von Helversen, O., Lina, P.H.C., Hutson, A.M., 2007. Bats of Britain, Europe and Northwest Africa. Franck-Kosmos Verlags, London. UK. 400pp. 
Dormann, C.F., McPherson, J.M., Araújo, M.B., Bivand, R., Bolliger, J., Carl, G., Richard G. D., Hirzel, A., Jetz, W., Kissling, W.D., Kühn, I., Ohlemüller, R., Peres-Neto, P.R., Reineking, B., Schröder, B., Schurr, F.M., Wilson, R. 2007. Methods to account for spatial autocorrelation in the analysis of species distributional data: a review. Ecography. 30, 609-628.

Dunsmore, J., L. S. Hall, and K. H. Kottek. 1974. DDT in the bent-winged bat in Australia. Search, 5: 110-111.

ENR 2012. Syndicat des Energies Renouvelables. http://www.enr.fr/docs/2010122633_02FEEChiffresclesFrance.pdf

Erickson, W.P., Johnson, G.D., Young, D., Strickland, D., Good, R., Bourassa, M., Bay, K., Sernka, K., 2002. Synthesis and comparison of baseline avian and bat use, raptor nesting and mortality information from proposed and existing wind developments. Bonneville Power Administration, Portland, Oregon, USA. 129 pp.

Faraway, J.J., 2006. Extending the linear model with R, Generalized linear, mixed effects and nonparametric regression models. Chapman and Hall/CRC. Boca Raton. 301pp.

Fuentes-Montemayor, E., Goulson, D., Park, K.J., 2011. Pipistrelle bats and their prey do not benefit from our widely applied agri-environment management prescriptions. Biological Conservation. 144, 2233-2246.

Fox, J., Monette G., 1992. Generalized collinearity diagnostics. Journal of the American Statistical Association. 87, 178-183.

French Bat Monitoring Programme (FBMP) 2012, http://vigienature.mnhn.fr/chauves-souris

Gannon, W.L., O’Farell, M.J., Corben, C., Bedrick, E., 2004. Call character Lexicon and analysis of field recorded bat echolocation calls. Echolocation in bats and dolphins. Edited by J.A. Thomas, CF Moss, and Vater. 2004. University of Chicago Press, Chicago, IL, USA, 604 pp.

Holderied, M.W., Von Helversen, O., 2003. Echolocation range and wingbeat period match in aerial-hawking bats. Proceedings of the Royal Society B: Biological Sciences. 270, 2293 -2299.

Hole, D.G., Perkins, A.J., Wilson, J.D., Alexander, I.H., Grice, P.V., Evans, A.D., 2005. Does organic farming benefit biodiversity? Biological Conservation. 122, 113-130.

Horn, J.W., Arnett, E.B., Kunz, T.H. 2008. Behavioral responses of bats to operating wind turbines. Journal of Wildlife Management. 72, 123-132.

Hötker. H., Thomsen, K.M., Jeromin, H., 2006. Impacts on biodiversity of exploitation of renewable energy sources: the example of birds and bats - facts, gaps in knowledge, demands for further research, and ornithological guidelines for the development of renewable energy exploitation. Michael-Otto-Institut im NABU, Bergenhusen. 65pp. 
INSEE 2012. Institut national de la statistique et des études économiques. http://www.insee.fr/fr/themes/tableau.asp?reg_id=99\&ref_id=t_3501R

Jennings, N., Pocock, M.J.O., 2009. Relationships between sensitivity to agricultural intensification and ecological traits of insectivorous mammals and arthropods. Conservation Biology. 23, 1195-1203.

Jones, G., Jacobs, D.S., Kunz, T.H., Willig, M.R., Racey, P.A., 2009. Carpe noctem: the importance of bats as bioindicators. Endang Species Res. 8, 93-115.

Johnson, G. D., Erickson, W. P., Strickland, M. D, Shepherd, M. F., Shepherd, D. A., Sarappo, S. A., 2003. Mortality of bats at a large-scale wind power development at Buffalo Ridge, Minnesota. American Midland Naturalist. 150, 332-342.

Kleijn, D., Baquero, R.A., Clough, Y., Diaz, M., De Estaban, J., Fernandez, F., Gabriel, D., Herzog, F., Holzschuh, A., Jöhl, R., Knop, E., Kruess, A., Marshall, E.J.P., Steffan-Dewenter, I., Tscharntke, T., Verhulst, J., West, T.M., Yela, J.L., 2006. Mixed biodiversity benefits of agrienvironment schemes in five European countries. Ecology Letters. 9, 243-254.

Kleijn, D., Sutherland, W.J., 2003. How effective are European agri-environment schemes in conserving and promoting biodiversity? Journal of applied ecology. 40, 947-969.

Kunz, T.H. and M. B. Fenton. 2003. Bat ecology Chicago, IL University of Chicago Press. 798 pp.

Kunz, T.H., Arnett, E.B., Cooper, B.M., Erickson, W.P., Larkin, R.P., Mabee, T., Morrison, M.L., Strickland, M.D., Szewczak, J.M., 2007a. Assessing Impacts of Wind-Energy Development on Nocturnally Active Birds and Bats: A Guidance Document. Journal of Wildlife Management. 71, 2449-2486.

Kunz, T.H., Arnett, E.B., Erickson, W.P., Hoar, A.R., Johnson, G.D., Larkin, R.P., Strickland, M.D., Thresher, R.W., Tuttle, M.D., 2007b. Ecological impacts of wind energy development on bats: questions, research needs, and hypotheses. Front Ecol Environ. 5, 315-324.

Kuvlesky, W.P., Brennan, L.A., Morisson, M.L., Boydston, K.K., Ballard, B.M., Bryant, F.C., 2007. Wind Energy Development and Wildlife Conservation: Challenges and Opportunities. Journal of Wildlife Management. 71, 2487-2498.

Lehnert, L.S., Kramer-Schadt, S., Schönborn, S., Lindecke, O., Niermann, I., Voigt, C.C., 2014. Wind farm facilities in Germany kill Noctule bats from near and far. PloS ONE. 9, e103106.

Lentini, P.E., Gibbons, P., Fischer, J., Law, B., Hanspack, J., Martin, T.G., 2012. Bats in a farming landscape benefit from linear remnant and unimproved pasture. Plos ONE. 7, e48201.

Lloyd, B.D., 2010. Resource consent applications by Contact Wind Limited relating to the Hauauru Ma Raki Wind Farm Proposal. www.mfe.govt.nz 
Mac Nally, R., 2000. Regression and model building in conservation biology, biogeography and ecology: the distinction between and reconciliation of 'predictive' and 'explanatory' models. Biodiversity and Conservation. 9, 655-671.

Maron, M., Hobb, R.J., Moilanen, A., Matthews, J.W., Christie, K., Gardner, T.A., Keith, D.A., Lindenmayer, D.B., McAlpine, C.A. 2012. Faustian bargains? Restoration realities in the context of biodiversity offset policies. Biological Conservation. 155, 141-148.

McKenney, B.A., Kiesecker, J.M., 2010. Policy Development for Biodiversity Offsets: A Review of Offset Frameworks. Environmental Management. 45, 165-176.

Merckx, T., Feber, R.E., Riordan, P., Townsend, M.C., Bourn, N.A.D., Parsons, M.S., Macdonald, D.W., 2009. Optimizing the biodiversity gain from agri-environment schemes. Agriculture, Ecosystems \& Environment. 130, 177-182.

Mitchell-Jones, A.J., Z. Bihari, M. Masing, and L. Rodrigues. 2007. Protecting and managing underground sites for bats. EUROBATS Publication Series No. 2 (English version). UNEP / EUROBATS Secretariat, Bonn, Germany, 38 pp.

Northrup, J.M., Wittemyer, G., 2013. Characterising the impacts of energy development on wildlife, with an eye towards mitigation. Ecology Letters. 16, 112-125.

Obrist, M.K., Boesch, R., Flückiger, P.F., 2004. Variability in echolocation call design of 26 Swiss bat species: consequences, limits and options for automated field identification with a synergetic pattern recognition approach. Mammalia. 68, 307-322.

Penone, C., Le Viol, I., Pellissier, V., Julien, J-F., Bas, Y., Kerbiriou, C. 2013. Assessing anthropogenic pressures on Orthoptera communities using large scale acoustic monitoring. Conservation Biology. 27, 979-987.

Quétier, F., Lavorel, S., 2011. Assessing ecological equivalence in biodiversity offset schemes: key issues and solutions. Biological Conservation. 144, 2991-2999.

Racey, P.A., 2009. Bats: status, threats and conservation successes. Introduction. Endang Species Res. 8, 1-3.

Rainho, A. 2007. Summer foraging habitats of bats in a Mediterranean region of the Iberian Peninsula. Acta Chiropterologica, 9 : 171-181.

Regnery, B., Couvet, D., Kerbiriou, C. 2013a. Offset measures and development projects: the conservation of protected species under the EU Birds and Habitats Directives. Conservation Biology. 27, 1335-1343.

Regnery, B., Kerbiriou, C., Julliard, R., Vandevelde, J-C., Le Viol, I., Burylo M., Couvet, D. 2013b. Sustain common species and ecosystem functions through biodiversity offsets: response to Pilgrim et al.. Conservation Letters. 6, 385-386. 
Rodrigues, L., Bach, L., Dubourg-Savage, M. J., Goodwin, J., Harbusch, C., 2008. Guidelines for consideration of bats in wind farm projects. EUROBATS Publication Series $N^{\circ} 3$. PNUE/EUROBATS Secrétariat, Bonn, Germany. 60pp.

Roscioni, F., Rebelo, H., Russo, D., Carranza, L.M., Di Febbraro, M., Loy, A., 2014. A modeling approach to infer the effects of wind farms on landscape connectivity for bats. Landscape Ecology. 29, 891-903.

Rydell, J., 2006. Bats and their insect prey at streetlights. in: Rich, C., Longcore, T., 2005. Ecological Consequences of Artificial Night Lighting. Island Press, Washington, D.C. pp. 43-60.

Rydell, J., Bach, L., Dubourg-Savage, M.-J., Green, M., Rodrigues, L., Hedenström, A., 2010. Bat mortality at wind turbines in northwestern Europe. Acta Chiropterologica. 12, 261-274.

Stahlschmidt, P., Brühl, C.A., 2012. Bats as bioindicators - the need of standardized method for acoustic bat activity surveys. Methodes in Ecology and Evolution 3, 503-508.

Stebbings, R.E., 1988. Conservation of European bats. Christopher Helm, London.

Schnitzler, H.U., Moss, C.F., Denzinger, A., 2003. From spatial orientation to food acquisition in echolocating bats. Trends in Ecology \& Evolution. 18, 386-394.

Stone, E.L., Jones, G., Harris, S., 2012. Conserving energy at a cost to biodiversity? Impacts of LED lighting on bats. Global Change Biology. 18, 2458-2465.

Stone, E.L., Jones, G., Harris, S., 2013. Mitigating the effect of development on bats in England with derogation licensing. Conservation Biology. 27, 1324-1334.

Swanepoel, R. E., P. A. Raceya, R. F. Shore, and J. R. Speakman. 1999. Energetic effects of sublethal exposure to lindane on pipistrelle bats (Pipistrellus pipistrellus) Environmental Pollution, 104: 169-177.

Swift, S., Racey, P., 2002. Gleaning as a foraging strategy in Natterer's bat Myotis nattereri. Behavioral Ecology and Sociobiology. 52, 408-416.

Taylor, M.E, Morecroft, M.D., 2009. Effects of agri-environment schemes in a long-term ecological time series. Agriculture, Ecosystems \& Environment. 130, 9-15.

UICN 2011. http://www.uicn.fr/Liste-rouge-mondiale-2011.html

US Environmental Protection Agency \& US Department of the Army (US EPA and DA), 1990. Memorandum of agreement between the Environmental Protection Agency and the Department of the Army concerning the determination of mitigation under the Clean Water Act Section 404 guidelines. http://water.epa.gov/lawsregs/guidance/wetlands/mitigate.cfm 
Walsh, A. L., Harris, S., 1996. Factors determining the abun- dance of vespertilionid bats in Britain: geographical, land class and local habitat relationships. Journal of Applied Ecology. 33, 519-529.

Wickramasinghe, L.P., Harris, S., Jones, G., Vaughan, N., 2003. Bat activity and species richness on organic and conventional farms: impact of agriculture intensification. Journal of Applied Ecoly. 40, 984:993.

Wittingham, M.J., 2011. The future of agri-environment schemes: biodiversity gains and ecosystem service delivery? Journal of Applied Ecology. 48, 509:513.

WWEA 2010, World Wind Energy Association, www.wwindea.org/home/images/stories/pdfs/worldwindenergyreport2010_s.pdf 
Table 1: Number of bats passes per group and per visit (in parentheses: the $\%$ of the total number of contacts per visit)

\begin{tabular}{lcccc}
\hline Group & Pipistrellus & Eptesicus-Nyctalus & Plecotus-Myotis & Total \\
\hline First visit & $3587(91 \%)$ & $173(5 \%)$ & $166(4 \%)$ & 3926 \\
Second visit & $5611(94 \%)$ & $195(3 \%)$ & $179(3 \%)$ & 5985 \\
Sum of the two visit & $9198(93 \%)$ & $368(4 \%)$ & $345(3 \%)$ & 9911 \\
\hline
\end{tabular}

Table 2: $\beta$ parameters \pm standard errors (SE) and $p$-values from a Generalized Linear Model of bat activity with a distance-weighted function for the Pipistrellus group ( $1^{\text {st }}$ visit) and the Eptesicus-Nyctalus group ( $\left.1^{\text {st }}\right)$. Crops without wind turbine (C) provides the intercept (i.e., the variable for which the parameter $=0$ ). A positive parameter (respectively, negative) indicates that the modality presents a higher (respectively, lower) abundance than C. CWT = Crops under wind turbine, $\mathrm{Fa}=$ Fallows, $\mathrm{H}=$ Hedgerows, $\mathrm{GS}=$ Grass strips, $\mathrm{B}=$ Bushes, $\mathrm{GSB}=$ Grass strips with bushes. Significant effects are in bold.

\begin{tabular}{|c|c|c|c|c|c|c|}
\hline & \multicolumn{3}{|c|}{ First visit } & \multicolumn{3}{|c|}{ Second visit } \\
\hline Group & Pipistrellus & $\begin{array}{l}\text { Eptesicus- } \\
\text { Nyctalus }\end{array}$ & $\begin{array}{l}\text { Plecotus- } \\
\text { Myotis }\end{array}$ & Pipistrellus & $\begin{array}{l}\text { Eptesicus- } \\
\text { Nyctalus }\end{array}$ & $\begin{array}{l}\text { Plecotus- } \\
\text { Myotis }\end{array}$ \\
\hline \multicolumn{7}{|l|}{ Modality } \\
\hline \multicolumn{7}{|l|}{$C W T$} \\
\hline$B \pm S E$ & $-0.59 \pm 0.64$ & $-1.08 \pm 1.15$ & $-0.22 \pm 0.49$ & $-0.56 \pm 0.69$ & $-0.55 \pm 0.39$ & $-0.03 \pm 0.56$ \\
\hline$p$-value & 0.355 & 0.346 & 0.656 & 0.414 & 0.156 & 0.962 \\
\hline \multicolumn{7}{|l|}{$\mathrm{Fa}$} \\
\hline$B \pm S E$ & $0.37 \pm 0.51$ & $0.35 \pm 0.67$ & $1.25 \pm 0.39$ & $1.09 \pm 0.56$ & $0.12 \pm 0.36$ & $0.86 \pm 0.51$ \\
\hline$p$-value & 0.465 & 0.597 & 0.00137 & 0.052 & 0.742 & 0.088 \\
\hline \multicolumn{7}{|l|}{$H$} \\
\hline$B \pm S E$ & $0.79 \pm 0.41$ & $0.32 \pm 0.75$ & $0.35 \pm 0.45$ & $-1.33 \pm 0.99$ & $-0.11 \pm 0.37$ & $0.50 \pm 0.54$ \\
\hline$p$-value & 0.055 & 0.675 & 0.431 & 0.177 & 0.768 & 0.353 \\
\hline \multicolumn{7}{|l|}{ GS } \\
\hline$B \pm S E$ & $-0.13 \pm 0.55$ & $1.63 \pm 0.49$ & $-1.00 \pm 0.78$ & $-1.47 \pm 0.74$ & $0.14 \pm 0.37$ & $0.33 \pm 0.57$ \\
\hline$p$-value & 0.805 & 0.000811 & 0.199 & 0.0449 & 0.715 & 0.565 \\
\hline \multicolumn{7}{|l|}{$B$} \\
\hline$B \pm S E$ & $-0.98 \pm 0.72$ & $-0.15 \pm 0.89$ & $-0.25 \pm 0.59$ & $0.11 \pm 0.51$ & $-0.29 \pm 0.42$ & $0.20 \pm 0.62$ \\
\hline$p$-value & 0.177 & 0.864 & 0.677 & 0.835 & 0.499 & 0.746 \\
\hline \multicolumn{7}{|l|}{$G S B$} \\
\hline$B \pm S E$ & $-0.29 \pm 0.64$ & $-0.29 \pm 0.69$ & $-0.11 \pm 0.54$ & $-1.02 \pm 0.70$ & $-1.93 \pm 0.83$ & $-0.41 \pm 0.73$ \\
\hline$p$-val & 0.639 & 0.673 & 0.842 & 0.145 & 0.019 & 0.571 \\
\hline
\end{tabular}


Figure 1: Sampling design map

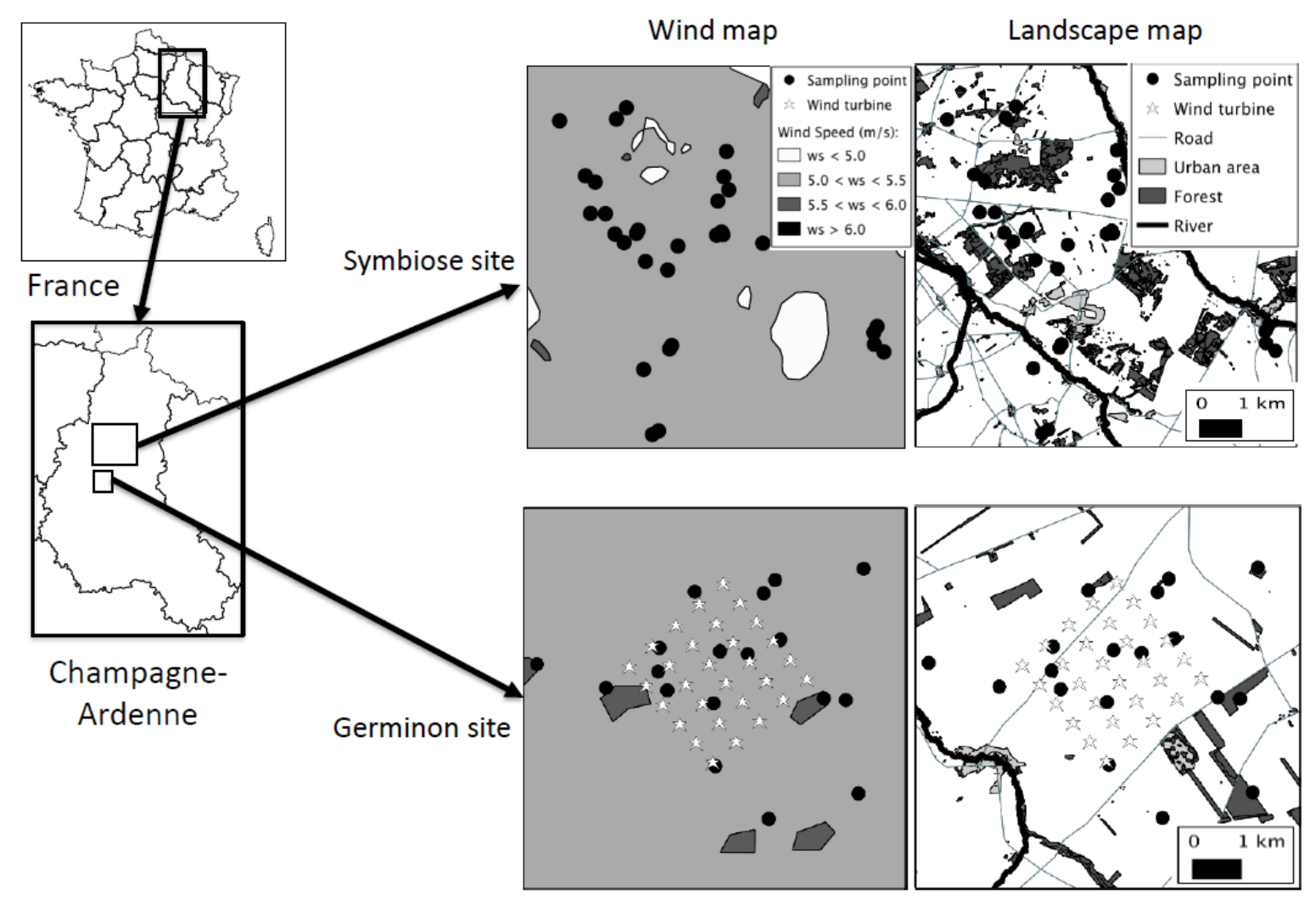


Figure 2: Results from the Mixed Generalised Linear models of bat activity for the first visit (respectively, second) on the left (respectively, on the right), with a distance-weighted function for the $1^{\text {st }}$ visit. Crops without wind turbine (C) provided the intercept (i.e., the variable for which the parameter $=0$, bold black line). A positive parameter (respectively, negative) means that the site type presents a higher (respectively, lower) abundance than $C$. $\mathrm{CWT}=$ Crops under wind turbine, $\mathrm{Fa}=$ Fallows, $\mathrm{H}=$ Hedgerows, $\mathrm{GS}=$ Grass strips, $\mathrm{B}=$ Bushes, $\mathrm{GSB}=$ Grass strips with bushes. The number of stars indicates the significance level $(* * *: p-$ value $<0.001,{ }^{* *}: 0.001<p$-value $<0.01$ and ${ }^{*}: 0.01<p$-value $\left.<0.05\right)$.
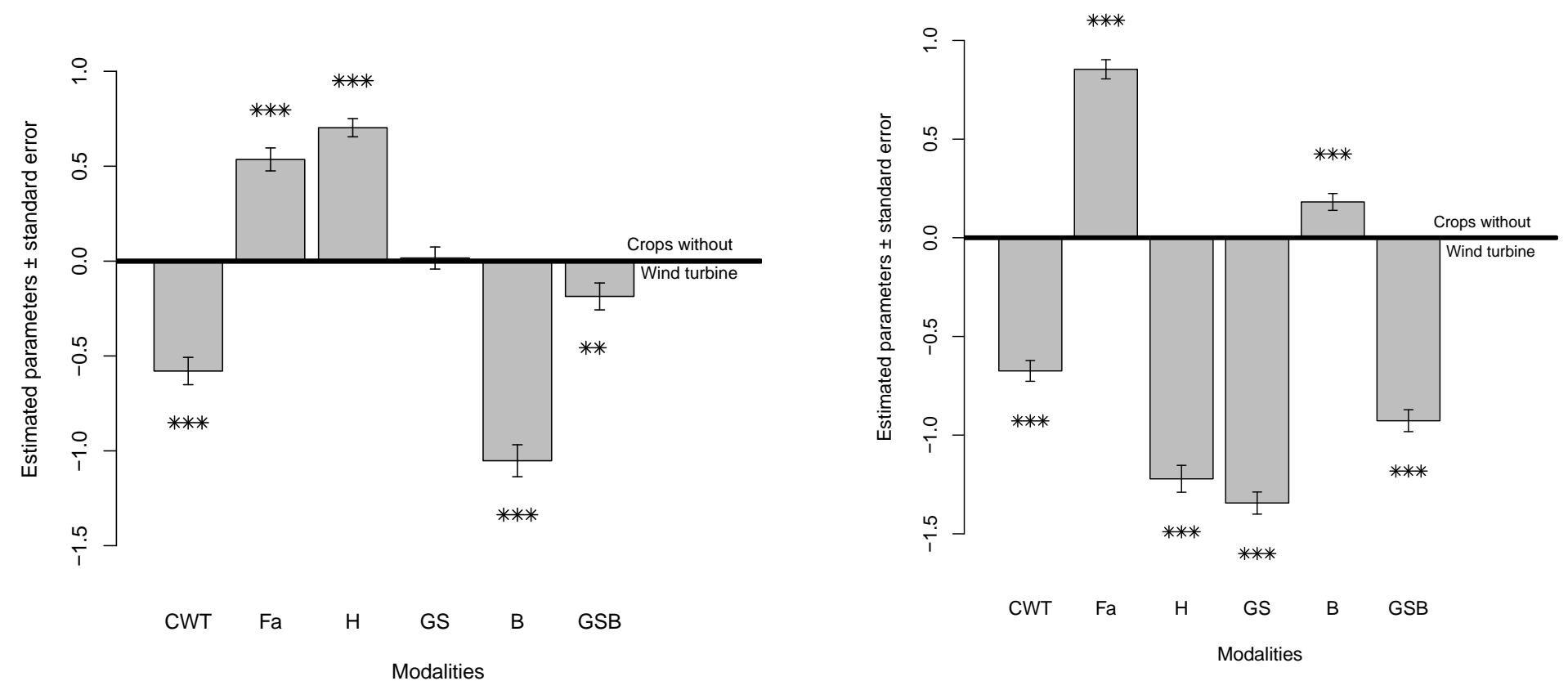


\section{Electronic supplementary material A: Bat activities records}

\section{Bat detector}

Song Meters II detectors were used to automatically and directly record ultrasound while maintaining all characteristics of the original signals (Stahlschmidt et al., 2012).

\section{$\underline{2 \text { The main relevant parameters used were: }}$}

Call duration (msec)

Time elapsed since previous detection (msec)

Maximum frequency detected (Fmax, $\mathrm{KHz}$ )

Minimum frequency detected ( $\mathrm{Fmin}, \mathrm{KHz})$

Total Bandwidth [Fmax - Fmin] (KHz)

Frequency at strongest sound pressure level $(\mathrm{KHz})$

Location of Dominant Frequencies (\% of total duration)

High end of characteristic (KHz) [Similar to Fk]

Low end of characteristic $(\mathrm{KHz})$ [Similar to $\mathrm{Fc}$ ]

Global slope of the call ( $\mathrm{KHz}$ per msec)

Time of the heel or High Fc (percent of duration)

Upper slope [start to High Fc] (KHz per msec)

Lower slope [High Fc to Low Fc] (KHz per msec)

Fundamental frequency $(\mathrm{KHz})$

2nd harmonic frequency $(\mathrm{KHz})$

Curvature measurement as a way to characterize the shape of bat calls (see Jolly 1997)

Curve fit error parameter; a measurement of how much error exists between the curvature model and the actual shape of the call

\section{Assessment of bat pass length:}

We used data from the French Bat Monitoring Programme (FBMP). This monitoring is based on standardized recordings echolocation bat calls. The latter scheme was launched in 2006 and offered a dataset that included currently 28 species and 960500 bat calls. The objective of the scheme is to provide information on bat population trends and distributions in France. The FBMP includes 3 different versions of protocol: road survey by car, count point with small or large recorded period ( $6 \mathrm{~min} v s$ night). Here after we have used only data from the count point protocol $(6 \mathrm{~min})$. This protocol consists of a square of $2 \mathrm{~km}$-side randomly chosen (by the Museum) in a radius of $10 \mathrm{~km}$ from the observer's home, within which the observer chooses ten points. Five points at least are representative of the habitats of the square, the others being located in 'favorable' places for bats such as river banks and wood edges, etc. This sampling design allowed to obtain a quite good correlation between proportion of habitat sampled and proportion of habitat existing at the national scale $\left(R^{2}=0.94\right)$. Bat calls were detected using a Tranquility Transect Bat detector (Courtpan Design Ltd, UK) and recorded over 6 minutes on a Zoom H2 digital recorder (Samson technologies, USA). All detectors were calibrated at the French National Museum History in order to obtain the same level of sensibility. Signal from the condenser microphone of the bat detector was internally amplified and high pass filtered with a $5 \mathrm{kHz}$ corner frequency and fed to the Zoom 
$\mathrm{H} 2$ which recorded it at 96000 sample/s as PCM files. Sound was stored on Secured Card in Waveform Audio File Format more commonly known as WAV format, a format without compression. We stored the same bat signal with the two possible outputs of the detector: time expansion and high frequency. Here we used the high frequency outputs that allow considers the duration of bat call passes. Volunteers are not requested to identify high frequency format and thus few identification of the FBMP come from this format. Bat detector are placed at each station at 1.50 meters above the ground, with its microphone faces oriented to the sky with an angle of $45^{\circ}$ to the horizontal. During the 6 minutes of recording no movement or lighting is authorized. The ten points were sampled during the same night. The observers begin their sampling thirty minutes after dusk, in the same order for each visit (from season to season, and from year to year). Observers sampled bats only when weather conditions were favorable (no rain, temperature higher than $12^{\circ} \mathrm{C}$ and wind speed less than $5 \mathrm{~m} / \mathrm{sec}$ ).

Figure S1. Average of bat pass length per species. The number of measurements per species is indicated in parenthesis.

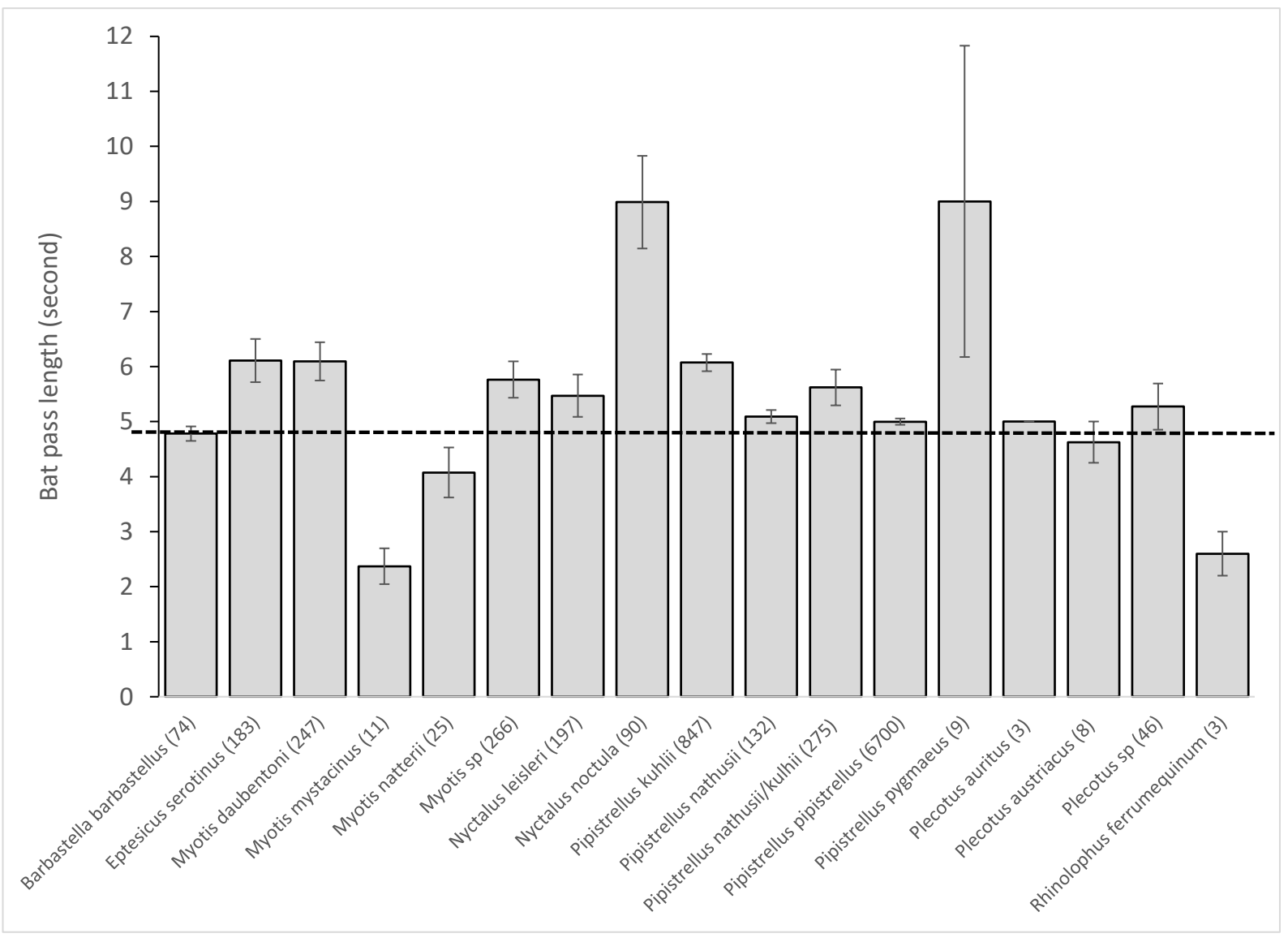

\section{Composition of each group}

The Pipistrellus group included Pipistrellus pipistrellus (78\%), P. nathusii (0.2\%), P. kuhlii (0.1\%) and $P$. pygmaeus $(0.1 \%)$. The remaining species were tandems unspecified and particularly P. pipistrellus-nathusii (21\%). The Eptesicus-Nyctalus group was composed of Nyctalus noctula (10\%), N. leisleri (8\%) and Eptesicus serotinus (3\%); the rest belonged to 
one of those three species. The Plecotus-Myotis group contained Plecotus auritus, $P$. austriacus (23\%), Myotis myotis (7\%), M. nattereri (6\%), Myotis bechsteinii (1\%) and $M$. daubentonii (1\%). The rest (62\%) of this group were Myotis sp undetermined at the species level.

\section{References}

Stahlschmidt, P., Brühl, C.a., 2012. Bats as bioindicators - the need of standardized method for acoustic bat activity surveys. Method.Ecol.Evol 3. 503-508. 
Electronic supplementary material B: Results from the data set with $\mathbf{5}$ additional sampling points during the second visit

Table S1: $\beta$ parameters \pm standard errors (SE) and $p$-values from a Generalized Linear Model of bat activity. Crops without wind turbine (C) is the intercept (i.e., the variable for which the parameter $=0$ ). A positive parameter (respectively, negative) means that the modality presents a higher (respectively, lower) abundance than C. CWT = Crops under wind turbine, $\mathrm{Fa}=$ Fallows, $\mathrm{H}=$ Hedgerows, GS = Grass strips, B = Bushes, GSB = Grass strips with bushes. Significant effects are in bold.

\begin{tabular}{|c|c|c|c|c|c|c|}
\hline & \multicolumn{3}{|c|}{$\begin{array}{c}\text { Second visit with common sampling } \\
\text { points with in the first visit (presented in } \\
\text { table } 2 \text { in Results) }\end{array}$} & \multicolumn{3}{|c|}{$\begin{array}{l}\text { Second visit with } 5 \text { additional sampling } \\
\text { points }\end{array}$} \\
\hline & Pipistrellus & $\begin{array}{l}\text { Eptesicus- } \\
\text { Nyctalus }\end{array}$ & $\begin{array}{l}\text { Plecotus- } \\
\text { Myotis }\end{array}$ & Pipistrellus & $\begin{array}{l}\text { Eptesicus- } \\
\text { Nyctalus }\end{array}$ & $\begin{array}{l}\text { Plecotus- } \\
\text { Myotis }\end{array}$ \\
\hline \multicolumn{7}{|l|}{ Modality } \\
\hline \multicolumn{7}{|l|}{$C W T$} \\
\hline$B \pm S E$ & $-0.56 \pm 0.69$ & $-0.55 \pm 0.39$ & $-0.03 \pm 0.56$ & $-0.61 \pm 0.69$ & $-0.54 \pm 0.39$ & $-0.03 \pm 0.55$ \\
\hline$p$-value & 0.414 & 0.156 & 0.961 & 0.374 & 0.166 & 0.957 \\
\hline \multicolumn{7}{|l|}{$\mathrm{Fa}$} \\
\hline$B \pm S E$ & $1.09 \pm 0.56$ & $0.12 \pm 0.36$ & $0.86 \pm 0.51$ & $1.00 \pm 0.69$ & $0.24 \pm 0.34$ & $0.79 \pm 0.48$ \\
\hline$p$-value & 0.052 & 0.742 & 0.088 & 0.09 & 0.488 & 0.102 \\
\hline \multicolumn{7}{|l|}{$H$} \\
\hline$B \pm S E$ & $-1.33 \pm 0.99$ & $-0.11 \pm 0.37$ & $0.50 \pm 0.54$ & $-1.41 \pm 1.00$ & $-0.11 \pm 0.37$ & $0.44 \pm 0.53$ \\
\hline$p$-value & 0.177 & 0.768 & 0.353 & 0.184 & 0.774 & 0.404 \\
\hline \multicolumn{7}{|l|}{ GS } \\
\hline$B \pm S E$ & $-1.47 \pm 0.74$ & $0.14 \pm 0.37$ & $0.33 \pm 0.57$ & $-1.53 \pm 0.74$ & $0.12 \pm 0.37$ & $0.33 \pm 0.55$ \\
\hline$p$-value & 0.0449 & 0.715 & 0.565 & 0.039 & 0.751 & 0.552 \\
\hline \multicolumn{7}{|l|}{$B$} \\
\hline$B \pm S E$ & $0.11 \pm 0.51$ & $-0.29 \pm 0.42$ & $0.20 \pm 0.62$ & $0.10 \pm 0.52$ & $-0.10 \pm 0.38$ & $0.14 \pm 0.58$ \\
\hline$p$-value & 0.835 & 0.499 & 0.746 & 0.846 & 0.788 & 0.814 \\
\hline \multicolumn{7}{|l|}{$G S B$} \\
\hline$B \pm S E$ & $-1.02 \pm 0.70$ & $-1.93 \pm 0.83$ & $-0.41 \pm 0.73$ & $-0.89 \pm 0.71$ & $-1.94 \pm 0.83$ & $-0.42 \pm 0.71$ \\
\hline$p$-value & 0.145 & 0.019 & 0.571 & 0.206 & 0.019 & 0.560 \\
\hline
\end{tabular}


Table S2: $\beta$ parameters \pm standard errors (SE) and $p$-values from a Mixed Model on bat activity. Crops without wind turbine (C) is the intercept (i.e., the variable for which the parameter $=0$ ). A positive parameter value (respectively, negative) means that the site type presents a higher (respectively, lower) abundance than C. CWT = Crops under wind turbine, $\mathrm{Fa}=$ Fallows, $\mathrm{H}=$ Hedgerows, GS = Grass strips, B = Bushes, GSB = Grass strips with bushes. Significant effects are in bold.

\begin{tabular}{|c|c|c|}
\hline & $\begin{array}{c}\text { Second visit with common } \\
\text { sampling points with in the first } \\
\text { visit (presented in Fig } 2 \text { on the } \\
\text { right) }\end{array}$ & $\begin{array}{l}\text { Second visit with } 5 \\
\text { additional sampling points }\end{array}$ \\
\hline \multicolumn{3}{|l|}{ Modality } \\
\hline \multicolumn{3}{|l|}{$C W T$} \\
\hline$B \pm S E$ & $-0.67 \pm 0.05$ & $-0.70 \pm 0.05$ \\
\hline$p$-value & $<0.0001$ & $<0.0001$ \\
\hline \multicolumn{3}{|l|}{$\mathrm{Fa}$} \\
\hline$B \pm S E$ & $0.85 \pm 0.05$ & $0.68 \pm 0.05$ \\
\hline$p$-value & $<0.0001$ & $<0.0001$ \\
\hline \multicolumn{3}{|l|}{$H$} \\
\hline$B \pm S E$ & $-1.22 \pm 0.07$ & $-1.24 \pm 0.07$ \\
\hline$p$-value & $<0.0001$ & $<0.0001$ \\
\hline \multicolumn{3}{|l|}{$G C$} \\
\hline$B \pm S E$ & $-1.34 \pm 0.06$ & $-1.30 \pm 0.06$ \\
\hline$p$-value & $<0.0001$ & $<0.0001$ \\
\hline \multicolumn{3}{|l|}{$B$} \\
\hline$B \pm S E$ & $0.18 \pm 0.04$ & $-0.05 \pm 0.04$ \\
\hline$p$-value & $<0.0001$ & 0.271 \\
\hline \multicolumn{3}{|l|}{$G S B$} \\
\hline$B \pm S E$ & $-0.93 \pm 0.06$ & $-0.82 \pm 0.06$ \\
\hline$p$-value & $<0.0001$ & $<0.0001$ \\
\hline
\end{tabular}




\section{Electronic supplementary material C: Tests of independence between variables.}

\section{Distribution of habitat landscape characteristics among site types}

To avoid biases with respect to bat activities due to the surrounding habitat, a proxy of habitat characteristics (i.e., continuous variables: distance to nearest forest, distance to nearest river and distance to nearest urban area) were checked for homogeneity among site types (i.e., categorical variables: 7 categories) using Kruskal-Wallis tests. The distribution was assumed to be homogeneous among site types when the resulting $p$-value $>0.05$. We did not detect any important correlation between the surrounding habitat and the site type except for the variable "distance to nearest forest" during the first visit, which exhibited a slightly significant trend (Table S1). Indeed, fallows were, on average, closer to the forest than the other site types (Fig S1).

Table S1: Results of Kruskal-Wallis tests between distances to habitat features (on a log scale) and the different site types.

\begin{tabular}{|c|c|c|c|}
\hline & $\begin{array}{l}\text { Log(distance to } \\
\text { nearest forest) }\end{array}$ & $\begin{array}{l}\text { Log(distance to } \\
\text { nearest river) }\end{array}$ & $\begin{array}{c}\text { Log(distance to } \\
\text { nearest urban area) }\end{array}$ \\
\hline \multicolumn{4}{|l|}{ First visit } \\
\hline ks & 14.9 & 7.16 & 10.8 \\
\hline$p$-value & 0.0214 & 0.307 & 0.0946 \\
\hline \multicolumn{4}{|l|}{ Second visit } \\
\hline ks & 11.6 & 5.98 & 11.6 \\
\hline$p$-value & 0.0726 & 0.425 & 0.0719 \\
\hline
\end{tabular}

Figure S1: Distribution of the forest distance (on a log scale) among site types. $C=$ Crops without wind turbine, CWT = Crops under wind turbine, $F a=$ Fallows, $H=$ Hedgerows, $G S=$ Grass strips, $B=$ Bushes, GSB $=$ Grass strips with bushes.

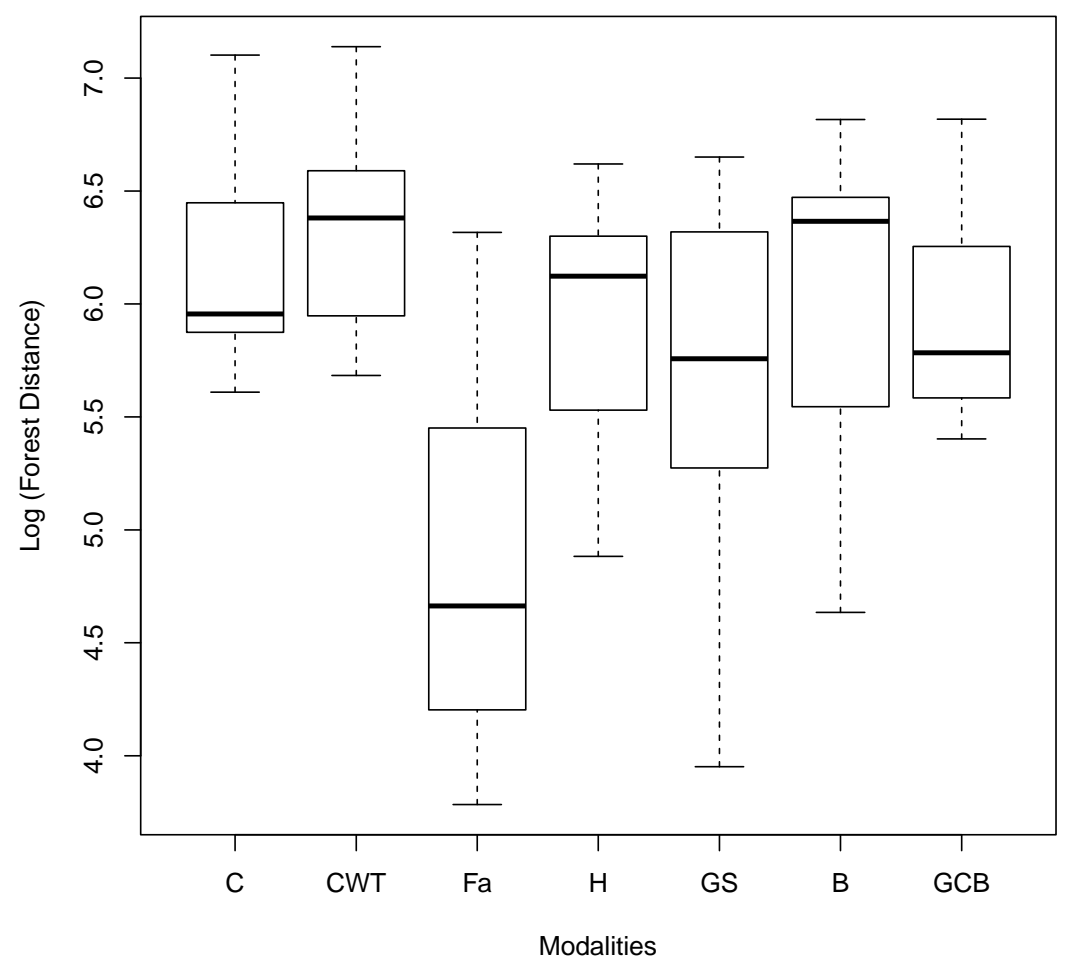




\section{Correlation between local field characteristics and site types}

With the aim of avoiding multicollinearity problems and possible confounding variables, we checked possible links between field characteristics and site types. When field characteristics were continuous variables (number of different crops, number of different linear features and crop mean height), we used Kruskal-Wallis tests, and when field characteristics were categorical variables (Beetroot presence, Rape presence, Cereal presence, Intermediate crop, Track presence and Field margin presence), we used a $\mathrm{Chi}^{2}$ test.

Only variables with a $p$-value higher than 0.05 were retained for further analysis.

Table S2: Results of Kruskal-Wallis tests between local field characteristic variables and modalities.

\begin{tabular}{|c|c|c|c|}
\hline & $\begin{array}{c}\text { Number of different } \\
\text { crops }\end{array}$ & $\begin{array}{c}\text { Number of different } \\
\text { linear features }\end{array}$ & Crops mean height \\
\hline \multicolumn{4}{|l|}{ First visit } \\
\hline ks & 17.5 & 9.93 & 11.4 \\
\hline$p$-value & 0.007 & 0.127 & 0.077 \\
\hline \multicolumn{4}{|l|}{ Second visit } \\
\hline ks & 20.7 & 6.28 & 17.8 \\
\hline$p$-value & 0.002 & 0.393 & 0.006 \\
\hline
\end{tabular}

Table S3: Results of $\mathrm{Chi}^{2}$ tests between all factorial variables available and the different site types. Due to farming management practices within a season, some crops were not present at each visit. Rape and cereals were harvested between visits, while intermediate crops were sown after those crops.

\begin{tabular}{|c|c|c|c|c|c|c|c|}
\hline & $\begin{array}{l}\text { Beetroot } \\
\text { presence }\end{array}$ & $\begin{array}{c}\text { Rape } \\
\text { presence }\end{array}$ & $\begin{array}{c}\text { Cereal } \\
\text { presence }\end{array}$ & $\begin{array}{c}\text { Alfalfa } \\
\text { presence }\end{array}$ & $\begin{array}{l}\text { Intermediate } \\
\text { crop }\end{array}$ & $\begin{array}{c}\text { Track } \\
\text { presence }\end{array}$ & $\begin{array}{c}\text { Field margin } \\
\text { presence }\end{array}$ \\
\hline \multicolumn{8}{|l|}{ First visit } \\
\hline & 22.7 & 31.3 & 24.9 & 26.6 & -- & & 29.51 \\
\hline$p$-value & 1 & 0.99 & 1 & 1 & -- & 0.99 & 0.99 \\
\hline \multicolumn{8}{|l|}{$\begin{array}{l}\text { Second } \\
\text { visit }\end{array}$} \\
\hline$\chi^{2}$ & 19.1 & -- & -- & 21.7 & 22.2 & 22.8 & 23.7 \\
\hline$p$-value & 1 & -- & -- & 1 & 1 & 1 & 1 \\
\hline
\end{tabular}

3 Calculation of luminosity during bat recording

Because the sampling sites were far enough from artificial light from villages, we calculated an index of natural luminosity based on the cloud cover, position of the moon and period when the moon was present. First, cloud cover was converted to an index of luminosity from 0.1 to $1,0.1$ when the sky was cloudy (we assumed that a night is never completely dark) and 1 when the sky was free of clouds. The moon position was also transformed into a luminosity index from 0.1 to $1,0.1$ for a new moon and 1 for a full moon. Finally, the duration of recording while the moon was present was calculated from moonset and 
moonrise data. For instance, imagine a night in which the data collection started at $9 \mathrm{PM}$ and stopped at $6 \mathrm{AM}$, and a moon only showed up at $4 \mathrm{AM}$; in this case, there were only two hours during which the moon was present out of 9 hours of recording, which means approximately $22 \%$ of the overall recording time. This percentage was transformed to an index from 0.1 to 1 , where 1 meant that the entire recording period occurred while the moon was present, whereas 0.1 meant that there was no moon at all during the recording time. The total luminosity of the night was the product of the cloud cover index, position of the moon and period when the moon was present.

\section{Correlation between meteorological variables and site types}

Given that our response variable "bat activities" might be affected by weather conditions, we recorded bat activity when weather conditions were favorable, but we also checked for possible correlations between weather conditions (i.e., a continuous variable) and site type using Kruskal-Wallis tests. Due to weak variation in weather conditions in our sample, we did not detect any link between weather condition and site type.

Table S4: Results of Kruskal-Wallis tests between meteorological continuous variables and the different site types.

\begin{tabular}{rccccc}
\hline & Precipitation & Wind speed & Temperature & Luminosity* & Julian date \\
\hline First visit & & & & & \\
ks & 6.4 & 10.03 & 5.2 & 7.3 & 10.2 \\
p-value & 0.380 & 0.123 & 0.518 & 0.294 & 0.118 \\
& & & & & \\
\hline Second visit & & & & & \\
ks & 2.2 & 8.6 & 3.3 & 1.6 & 1.3 \\
p-value & 0.904 & 0.188 & 0.764 & 0.954 & 0.971 \\
\hline
\end{tabular}

\section{$\underline{5 \text { Correlation between weather conditions }}$}

With the aim of detecting possible correlations among weather conditions (i.e., continuous variable), we used a Spearman correlation test. The important correlations between variables (correlation coefficient $\mid$ rho| $\geq 0.5$; Freckleton, 2002) are indicated in bold.

Table S5: Results of the Spearman correlation tests between meteorological variables

\begin{tabular}{llllll}
\hline & Precipitation & Wind speed & Temperature & Luminosity & Julian date \\
First visit & & & & \\
\hline Precipitation & - & $r=0.28$ & $r=-0.34$ & $r=0.03$ & $r=0.52$ \\
Wind speed & - & - & $r=-0.20$ & $r=0.00$ & $r=0.12$ \\
Temperature & - & - & $r=-0.17$ & $r=-0.01$ \\
Luminosity & - & - & - & $r=0.37$ \\
Julian Date & & & - & - \\
& & & & \\
Second visit & $r=0.32$ & $r=-0.55$ & $r=-0.26$ & $r=0.22$ \\
\hline Precipitation & - & $r=-0.36$ & $r=-0.21$ & $r=0.27$ \\
Wind speed & & & &
\end{tabular}




\begin{tabular}{llll}
- & - & $r=0.49$ & $r=-0.69$ \\
- & - & - & $r=-0.54$ \\
- & - & - & - \\
\hline
\end{tabular}

\section{Correlation between material variables and site types}

Finally, we checked potential links between site types and material variables (detector used, a categorical variable for which we used $\mathrm{Chi}^{2}$ tests and Length of record, a continuous variable for which we used Kruskal-Wallis tests). To avoid over-parameterization, only one of them was incorporated in further analysis. However, none of them have been selected in the final model because their effects were not significant.

The length of record differed among nights due to changes in sunset and sunrise hours (we always record from 30 minutes before sunset to 30 minutes after sunset) and due to technical problems (605 \pm 9.05 minutes per night; the minimum was 330 minutes per night and the maximum was 780 minutes per night). However, the peak bat activity begins 30 minutes after sunset and lasts 4 hours (Roche et al., 2005); we always recorded this period.

Table S6: Results of tests between material variables and site types

\begin{tabular}{|c|c|c|c|}
\hline & Detector used & & Length of recoro \\
\hline \multicolumn{4}{|l|}{ First visit } \\
\hline$\chi^{2}$ & 35.72 & ks & 6.10 \\
\hline$p$-value & 0.998 & $p$-value & 0.412 \\
\hline \multicolumn{4}{|l|}{ Second visit } \\
\hline$\chi^{2}$ & 32.6 & ks & 4.09 \\
\hline$p$-value & 0.996 & $p$-value & 0.664 \\
\hline
\end{tabular}

\section{Reference}

Freckleton, R.P. 2002. On the misuse of residuals in ecology: regression of residuals vs. multiple regression. Journal of Animal Ecology 71: 542-545.

Roche N., Catto C., Langton S., Aughney T. and Russ J. (2005). Development of a car-based bat monitoring protocol for the republic of ireland. Irish wildlife manuals, no. 19. National Parks and Wildlife Service, department of environment, heritage and local government, Dublin. 


\section{Electronic supplementary material D: List of selected variables in models}

Table S1. Complementary information on the variables included in each model (NS indicates that this variable has not been selected by the selection procedure). The significance of each selected variable is given via a $p$-value from an Anova type II with a Fisher test and the percentage of the explained variance ( $R$ package car). Because Anova tests are not possible in mixed models, significance was not calculated for variables in these models (unknown). The total explained variance and the AIC are given. 


\begin{tabular}{|c|c|c|c|c|c|c|c|c|}
\hline & \multicolumn{4}{|c|}{ First visit } & \multicolumn{4}{|c|}{ Second visit } \\
\hline & Pipistrellus & $\begin{array}{l}\text { Eptesicus- } \\
\text { Nyctalus }\end{array}$ & Plecotus-Myotis & $\begin{array}{l}\text { Overall } \\
\text { dataset }\end{array}$ & Pipistrellus & $\begin{array}{l}\text { Eptesicus- } \\
\text { Nyctalus }\end{array}$ & Plecotus-Myotis & $\begin{array}{l}\text { Overall } \\
\text { dataset }\end{array}$ \\
\hline Modality & $\begin{array}{c}62 \%(p- \\
\text { value }= \\
0.055)\end{array}$ & $\begin{array}{c}43 \% \text { (p-value }= \\
<0.0001)\end{array}$ & $\begin{array}{c}43 \% \text { (p-value }= \\
0.00557)\end{array}$ & Unknown & $\begin{array}{c}48 \% \text { (p-value }= \\
0.00977)\end{array}$ & $\begin{array}{c}17 \% \text { (p-value }= \\
0.0453)\end{array}$ & $\begin{array}{c}38 \% \text { (p-value }= \\
0.441)\end{array}$ & Unknown \\
\hline \multicolumn{9}{|c|}{ Local field characteristic variables } \\
\hline $\begin{array}{l}\text { Number of } \\
\text { different crops }\end{array}$ & NS & NS & NS & $N S$ & NS & NS & NS & NS \\
\hline $\begin{array}{l}\text { Number of } \\
\text { different linear } \\
\text { features }\end{array}$ & NS & NS & NS & NS & NS & NS & NS & Unknown \\
\hline $\begin{array}{l}\text { Crops mean } \\
\text { height }\end{array}$ & NS & NS & NS & Unknown & NS & NS & NS & NS \\
\hline $\begin{array}{l}\text { Beetroot } \\
\text { presence }\end{array}$ & NS & NS & NS & NS & NS & NS & NS & NS \\
\hline Rape presence & NS & $\begin{array}{c}5.9 \%(p-\text {-value }= \\
0.019)\end{array}$ & NS & $N S$ & NS & NS & NS & NS \\
\hline $\begin{array}{l}\text { Cereal } \\
\text { presence }\end{array}$ & NS & NS & NS & Unknown & NS & NS & NS & NS \\
\hline $\begin{array}{l}\text { Alfalfa } \\
\text { presence }\end{array}$ & NS & NS & NS & NS & NS & NS & NS & NS \\
\hline Intermediate & NS & NS & NS & NS & NS & NS & NS & Unknown \\
\hline
\end{tabular}


crop presence

\begin{tabular}{|c|c|c|c|c|c|c|c|c|}
\hline Track presence & NS & NS & NS & Unknown & NS & NS & NS & NS \\
\hline $\begin{array}{l}\text { Field margin } \\
\text { presence }\end{array}$ & NS & NS & $\begin{array}{c}32 \%(p-\text { value }= \\
0.000247)\end{array}$ & NS & $\begin{array}{c}15 \%(p-\text { value }= \\
0.0193)\end{array}$ & NS & NS & NS \\
\hline
\end{tabular}

\section{Meteorological variables}

\begin{tabular}{|c|c|c|c|c|c|c|c|c|}
\hline Precipitation & $N S$ & NS & NS & Unknown & NS & NS & NS & $N S$ \\
\hline Wind speed & NS & NS & NS & Unknown & $\begin{array}{c}37 \%(p \text {-value }= \\
0.000345)\end{array}$ & NS & NS & Unknown \\
\hline Temperature & NS & $\begin{array}{c}21 \%(p-\text {-value }= \\
<0.0001)\end{array}$ & NS & NS & NS & NS & NS & NS \\
\hline Luminosity & NS & NS & NS & NS & NS & NS & NS & NS \\
\hline Julian date & NS & & $\begin{array}{c}25 \%(p \text {-value }= \\
0.00108)\end{array}$ & NS & & $\begin{array}{c}83 \%(p \text {-value }= \\
<0.0001)\end{array}$ & $\begin{array}{c}62 \%(p \text {-value }= \\
0.00322)\end{array}$ & Unknown \\
\hline
\end{tabular}

Material variables

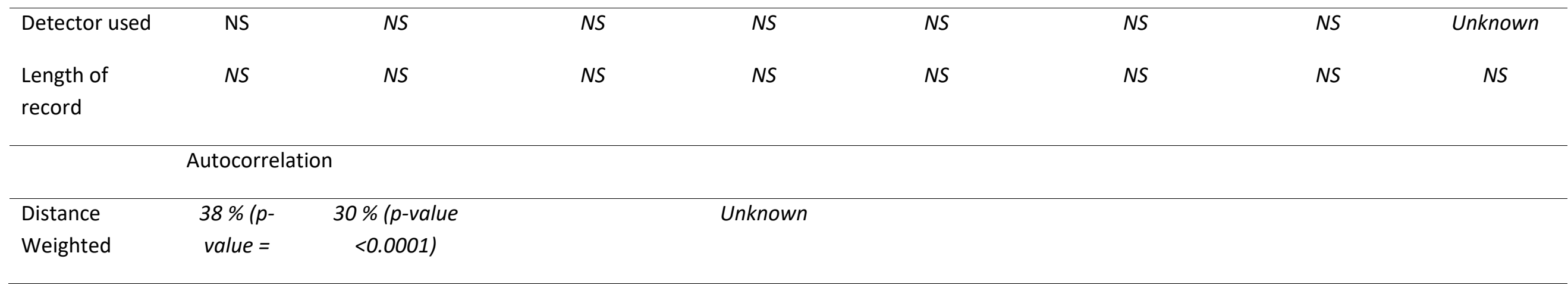


function 0.00599)

\begin{tabular}{lcccccccc}
\hline $\begin{array}{l}\text { Total explained } \\
\text { variance }\end{array}$ & $28 \%$ & $64 \%$ & $47 \%$ & Unknown & $44 \%$ & $61 \%$ & $23 \%$ & \\
\hline AIC & 3649 & 253 & 304 & Unknown & 6970 & 244 & 339 \\
\hline
\end{tabular}




\section{Electronic supplementary material E: Results from models in which is date controlled for meteorological variables}

Because recordings could be from the same night but different site types (i.e., for $85 \%$ of the nights), another type of statistical analysis was used that considered data from the same date as paired and thus allowed removal of the meteorological variables by including an adjustment for date, taken as a factor.

Table S1: Comparison between Generalized Linear Models with meteorological variables (Model 1 in table, see Table 2 for further precision) and Generalized Linear Models with Date as a factor variable (Model 2 in table). NS: Non significant results. The sign in parentheses is the sign of the parameter, +: significant positive trend, -: significant negative trend. Crops without wind turbine $(C)$ is the intercept (i.e., the variable for which the parameter $=0$ ). A positive parameter (respectively, negative) indicates that the modality presents a higher (respectively, lower) abundance than $\mathrm{C}$. CWT $=$ Crops under wind turbine, $\mathrm{Fa}=$ Fallows, $\mathrm{H}=$ Hedgerows, GS = Grass strips, B = Bushes, GSB = Grass strips with bushes.

\begin{tabular}{|c|c|c|c|c|c|c|c|c|c|c|c|c|}
\hline \multirow{3}{*}{$\begin{array}{l}\text { Group } \\
\text { Model }\end{array}$} & \multicolumn{6}{|c|}{ First visit } & \multicolumn{6}{|c|}{ Second visit } \\
\hline & \multicolumn{2}{|c|}{ Pipistrellus } & \multicolumn{2}{|c|}{$\begin{array}{l}\text { Eptesicus- } \\
\text { Nyctalus }\end{array}$} & \multicolumn{2}{|c|}{$\begin{array}{l}\text { Plecotus- } \\
\text { Myotis }\end{array}$} & \multicolumn{2}{|c|}{ Pipistrellus } & \multicolumn{2}{|c|}{$\begin{array}{l}\text { Eptesicus- } \\
\text { Nyctalus }\end{array}$} & \multicolumn{2}{|c|}{ Plecotus-Myotis } \\
\hline & 1 & 2 & 1 & 2 & 1 & 2 & 1 & 2 & 1 & 2 & 1 & 2 \\
\hline \multicolumn{13}{|l|}{ Modality } \\
\hline$C W T$ & NS & NS & NS & NS & NS & NS & NS & - & NS & NS & NS & NS \\
\hline $\mathrm{Fa}$ & NS & + & NS & NS & + & NS & + & NS & NS & NS & NS & NS \\
\hline$H$ & NS & + & NS & NS & NS & NS & NS & NS & NS & NS & NS & NS \\
\hline GS & NS & NS & + & NS & NS & - & - & - & NS & NS & NS & NS \\
\hline$B$ & NS & NS & NS & NS & NS & NS & NS & NS & NS & NS & NS & NS \\
\hline$G S B$ & NS & NS & NS & NS & NS & NS & NS & NS & NS & - & NS & NS \\
\hline
\end{tabular}


Table S2: Comparison between Mixed Generalized Linear Models with meteorological variables (Model 1 in table, see Figure 2 for graphical representation) and Mixed Generalized Linear Models with date as a factor variable (Model 2 in table). NS: Non-significant results. The sign in parentheses is the sign of the parameter, +: significant positive trend, -: significant negative trend. Crops without wind turbine (C) is the intercept (i.e., the variable for which the parameter $=0$ ). A positive parameter (respectively, negative) indicates that the site type presents a higher (respectively, lower) abundance than C. CWT $=$ Crops under wind turbine, $\mathrm{Fa}=$ Fallows, $\mathrm{H}=$ Hedgerows, GS $=$ Grass strips, $\mathrm{B}=$ Bushes, GSB $=$ Grass strips with bushes.

\begin{tabular}{rcccc}
\hline & \multicolumn{2}{c}{ First visit } & \multicolumn{2}{c}{ Second visit } \\
\hline Model & 1 & 2 & 1 & 2 \\
\hline $\begin{array}{r}\text { Modality } \\
\text { CWT }\end{array}$ & - & - & - & - \\
& & & & \\
Fa & + & + & + & + \\
$H$ & + & + & - & - \\
GS & NS & + & - & - \\
$B$ & - & - & + & - \\
GSB & - & NS & - & - \\
\hline
\end{tabular}




\section{Electronic supplementary material F: Parameters from the Mixed Models}

Table S1: $\beta$ parameters \pm standard errors (SE) and $p$-values from a Mixed Model on bat activity, with a distance-weighted function for the $1^{\text {st }}$ visit. Crops without wind turbine (C) is the intercept (i.e., the variable for which the parameter $=0$ ). A positive parameter value (respectively, negative) means that the site type presents a higher (respectively, lower) abundance than $\mathrm{C}$. CWT $=$ Crops under wind turbine, $\mathrm{Fa}=$ Fallows, $\mathrm{H}=$ Hedgerows, $\mathrm{GS}=$ Grass strips, $\mathrm{B}=$ Bushes, GSB = Grass strips with bushes. Significant effects are in bold. Those results are presented in the Fig 2.

\begin{tabular}{ccc}
\hline Modality & First Visit & Second visit \\
$C W T$ & & \\
$B \pm S E$ & $-0.58 \pm 0.07$ & $-0.67 \pm 0.05$ \\
$p$-value & $<0.0001$ & $<0.0001$ \\
Fa & & \\
$B \pm S E$ & $0.54 \pm 0.06$ & $0.85 \pm 0.05$ \\
$p$-value & $<0.0001$ & $<0.0001$ \\
$H$ & & \\
$B \pm S E$ & & $-1.22 \pm 0.07$ \\
$p$-value & $0.70 \pm 0.05$ & $<0.0001$ \\
$G C$ & $<0.0001$ & \\
$B \pm S E$ & & $-1.34 \pm 0.06$ \\
$p$-value & & $<0.0001$ \\
$B$ & $0.01 \pm 0.06$ & \\
$B \pm S E$ & 0.777 & $0.18 \pm 0.04$ \\
$p$-value & & $<0.0001$ \\
$G S B$ & $-1.05 \pm 0.08$ & \\
$B \pm S E$ & $<0.0001$ & $-0.93 \pm 0.06$ \\
$p$-value & & $<001$ \\
\hline
\end{tabular}

